STRUCTURAL BIOLOGY COMMUNICATIONS

ISSN 2053-230X

\section{Crystallization of a nonclassical Kazal-type Carcinoscorpius rotundicauda serine protease inhibitor, CrSPI-1, complexed with subtilisin. Corrigendum}

Rajesh T. Shenoy, ${ }^{\text {a* Saravanan Thangamani, }}{ }^{a}$ Bow Ho, ${ }^{b}$ J. Sivaraman ${ }^{a}$ and Jeak Ling Ding ${ }^{\mathrm{a}}$

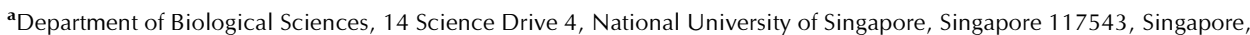
and ${ }^{\mathbf{b}}$ Department of Microbiology, 14 Science Drive 4, National University of Singapore, Singapore 117543, Singapore. *Correspondence e-mail: rajeshtshenoyone@gmail.com

Keywords: serine proteases; Kazal-type serine protease inhibitors; $\mathrm{CrSPI}$; corrigendum

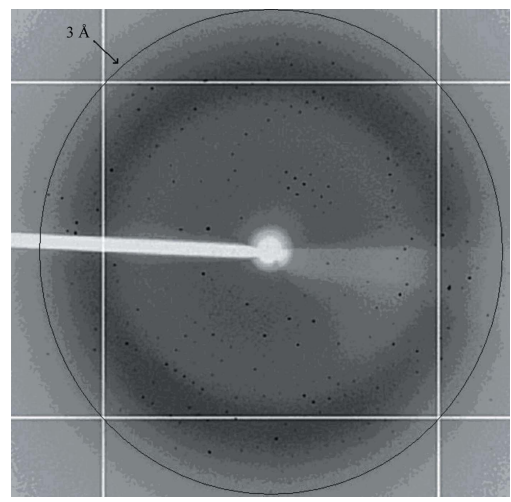

C 2020 International Union of Crystallography
The name of the first author in the article by Tulisas et al. [(2009), Acta Cryst. F65, 533-535] is corrected.

In the article by Tulsidas et al. (2009) the name of the first author was given incorrectly. The correct name is Rajesh $\mathrm{T}$. Shenoy as given here.

\section{References} (2009). Acta Cryst. F65, 533-535.
Tulsidas, S. R., Thangamani, S., Ho, B., Sivaraman, J. \& Ding, J. L. 